\title{
Performance of a Hydrocyclone for Separation of Hulls from Cotyledons of Some Grain Legumes
}

\author{
Ologunagba, F.O ${ }^{1}$., Imoukhuede, K. A $^{2}$. and Ibrahim, A.A ${ }^{1}$. \\ I'Department of Agricultural Engineering Technology, Rufus Giwa Polytechnic, P.M.B 1019, Owo, Nigeria) \\ ${ }^{2}$ (Department of Mechanical Engineering Technology, Rufus Giwa Polytechnic, P.M.B 1019, Owo, Nigeria)
}

\begin{abstract}
Hydrocyclone separators are favourable for various number of applications in the process industry due to its low investment cost, simplicity in design, compactness and low operation and maintenance cost. A hydrocyclone separator developed based on Rietman's optimum design for classification was evaluated for separation of hulls from the cotyledons of some dehulled legume seeds at 10, 20 and $30 \mathrm{~mm}$ under flow orifice diameters. Test results showed that the separator gave its best work performance at $20 \mathrm{~mm}$ underflow orifice diameter with separation efficiencies of 67.01, 65.80, 38.63 and $64.92 \%$ for common bean, cowpea, locust bean and soybean respectively. The use of the hydrocyclone for separation of hulls from cotyledons of dehulled grain legumes is therefore feasible. However, replaceable nozzles and mechanically adjustable orifices are necessary for improved performance.
\end{abstract}

Keywords: Efficiency, hydrocyclone, legume, separation, underflow orifice

\section{INTRODUCTION}

Legumes are among the three largest families of flowering plants and they belong to the family leguminosae. The plants in the family have characteristics leaves and pods that are used in identifying them. The seed coats (hulls) are usually tightly attached to the cotyledons [1]. Grain legumes are rich in protein and are only second to cereals as a source of human and animal food. In most developing countries of the world, they continue to occupy an important place in human nutrition as a solution to protein calorie malnutrition [2]. However, the maximum utilization of legume proteins is reduced by the toxic constituent often found in the seed coats, which interfere with the digestive processes of man and animal. $\beta$-amino prionitrate is found in the plant Lathyrus Sativus (grass pea), trypsin inhibitor in soybeans, cancer-producing mycotoxin, aflatoxin in groundnut and other toxic components of grain legumes such as lectins or haemogglutins, cyanogens and sapinins [3].

In order to fully utilize legume proteins, it is therefore necessary to remove the seed coats. Removal of the seed coats (dehulling) facilitates a reduction of fiber and tannin contents, and improvement in the appearance, texture, cooking time, palatability and digestibility of the grain [4]. The dehulling process may take place either with dry-raw whole seed in dry-dehulling or with soaked boiled grains in wet-dehulling depending on the desired food forms [5]. Most often, wet dehulling is commonly used for grain legumes and cereals for the production of viscous paste, powder or cake products such as 'akara' and 'moin-moin' commonly consumed as traditional foods in Nigeria and other African countries [6].

Traditionally, the sink-float separation method is used for separating the hulls from the cotyledons of the wet dehulled products. The dehulled products are poured into a basin of water, stirred with hand, and as the mixture settles, the floating hulls are skimmed off. Apart from the drudgery involved, this consumes a lot of time especially when dealing with large quantity. Sometimes, the process may need to be repeated severally before appreciable separation can be achieved. Therefore, a hydrocyclone based on Rietma's optimum design for classification was developed for the process [7].

This paper presents the performance of the hydrocyclone for the separation of hulls from cotyledon of some common grain legumes.

\subsection{Machine Description And Operation}

\section{MATERIALS AND METHODS}

The hydrocyclone is made up of the following component parts: The frame, cyclone, feed tank, collecting units and the prime mover. Fig 1 shows the isometric view of the hydrocyclone separator. The frame is made from $33 \mathrm{~mm} \times 33 \mathrm{~mm} \times 3 \mathrm{~mm}$ angle iron. It has a height of $700 \mathrm{~mm}$ and width of $360 \mathrm{~mm}$. The cyclone consists of two major parts, a cylindrical top section and lower conical section made of galvanized sheet metal. The top cylindrical section has a diameter of $350 \mathrm{~mm}$ and a height of $150 \mathrm{~mm}$. At the topmost part, it is fitted with a tangential feed connection (plastic pipe) of $50 \mathrm{~mm}$ diameter. The top is closed and is fitted with a downward protruding vortex finder of 50mm diameter plastic pipe that ends below the tangential feed location. The length of the vortex finder is $140 \mathrm{~mm}$. The lower conical section is below the cylindrical section and tapers 
downward into the heavier solid discharge outlet. It is directly welded to the cylindrical section and this increase the void of the cyclone. The shape of the section assists in the spiraling action and also increases the centrifugal forces acting. The conical section has a major diameter of $350 \mathrm{~mm}$ that tapers down to an opening (underflows orifice) designed in such a way that can be varied depending on the size and shape of the material to be separated.

The feed tank is cylindrical in shape and is also made of galvanized sheet metal. The tank has a stirrer for agitating the mixture and a cover that can be open to facilitate easy cleaning. It has a hopper with detachable sieve that receive the overflow with lighter solids, thus enhancing continuous flow. The feed tank has a diameter of $350 \mathrm{~mm}$ and a height of $380 \mathrm{~mm}$. A plastic pipe of $50 \mathrm{~mm}$ diameter is connected from the feed tank to the suction port of a pump. The pump is of centrifugal type that is lined with variable speed drive and of open impeller that is capable of handling liquids containing solids without becoming clogged.

The mixture in the feed tank is pumped tangentially into the stationary cono-cylindrical body with the aid of the pump, and due to the effect of the centrifugal forces created within the cyclone body, the incoming fluid moves in an outer helical flow into the outer portion of the inverted cone towards the apex, where some water with heavier particles (cotyledons) leave through the underflow orifice into the metal collecting plate (collector). The rest water with lighter particles (hulls) reverse the upward spiral direction to exit through the vortex finder (as overflow) to be collected on the detachable sieve on the hopper while the water recycles.

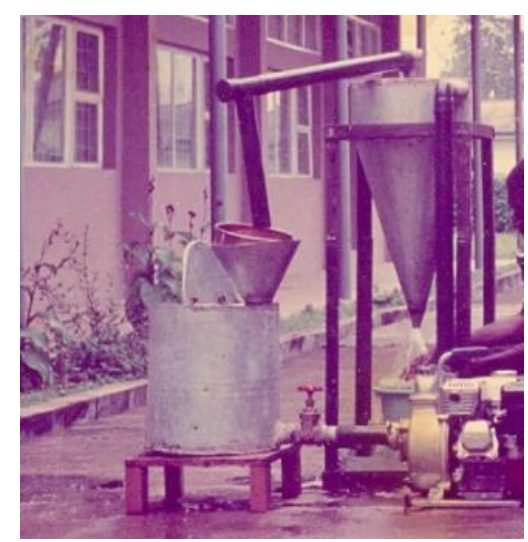

Plate 1. The hydrocyclone under test

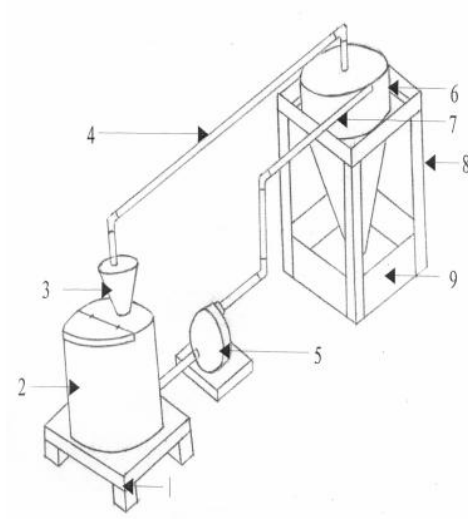

Fig 1. Isometric view of the hydrocyclone.

\subsection{Performance Evaluation}

The hydrocyclone was tested for its ability to separate the hulls from the cotyledons of dehulled legume seeds. Plate 1 shows the hydrocyclone under test. The test was carried out with four different grain legumes namely; common bean, cowpea, locust bean and soybean using 10, 20 and 30mm diameter underflow orifices.

Known weight of the dehulled legume seeds were loaded into the feed tank and pumped into the hydrocyclone until the whole mixture completely went through it. The recovered fractions of the cotyledons and hulls from the underflow and overflow were weighed and recorded. This procedure was repeated three times for each type of seed at a particular orifice and the average taken. The percentage mass recovery under flow, the percentage mass recovery overflow and the separation efficiency were determined using the expression in equations 1,2 and 3 respectively [8].

Percentage mass recovery underflow, $\mathrm{E}_{\mathrm{c}}=\mathrm{M}_{\mathrm{uc}} /\left(\mathrm{M}_{\mathrm{uc}}+\mathrm{M}_{\mathrm{oc}}\right) \times 100$

Percentage mass recovery overflow, $E_{h}=M_{o h} /\left(M_{o h}+M_{u h}\right) \times 100$

Separation Efficiency, $\quad \eta_{\mathrm{s}}=\mathrm{E}_{\mathrm{c}} \times \mathrm{E}_{\mathrm{h}}$

Where $M_{u c}=$ mass of cotyledons recovered at the underflow, $M_{o c}=$ mass of cotyledons recovered at the overflow, $\mathrm{M}_{\mathrm{uh}}=$ mass of hulls recovered at the underflow and $\mathrm{M}_{\mathrm{oh}}=$ mass of hulls recovered at the overflow.

\section{RESULTS AND DISCUSSION}

The evaluation result is presented in Table 1. The result shows that the performance of the hydrocyclone is greatly influence by the underflow orifice and the legume seed type. The test with $10 \mathrm{~mm}$ diameter underflow orifice for all the selected legume seeds has many of the cotyledons in the overflow because of crowding effect at the underflow orifice, and thus significant quantities of the cotyledons which should have passed through the underflow follow the hulls into the overflow thereby resulting in very low separation efficiency of 17.46, 16.04, 7.20 and $15.42 \%$ for common bean, cowpea, locust bean and soybean respectively.

When the underflow orifice was increased to $20 \mathrm{~mm}$, an appreciable sharpness of cut resulting in 67.01 , 65.80 and $64.92 \%$ separation efficiency was achieved for common bean, cowpea and soybean respectively. However, a relatively low separation efficiency of $38.63 \%$ was achieved for locust bean as a result of little difference in the densities of its cotyledons and hulls, indicating the absence of definite density difference that 
ought to exist between materials to be separated. Further increase of the underflow orifice to $30 \mathrm{~mm}$ diameter resulted in large quantities of the hulls flowing with the cotyledons to the underflow, thus resulting in loss of efficiency. These findings revealed that the underflow orifice has a pronounce effect on the volume split. Hence, correct adjustment of this variable is vital for excellent performance of the hydrocyclone. Therefore, replaceable nozzles or mechanically adjustable orifices are recommended for use to aid proper adjustment after start-up or during operation whenever some operation conditions change. However, for all the combined variables used for the test, the hydrocyclone performed best at $20 \mathrm{~mm}$ diameter underflow orifice for the selected grain legumes.

Table 1: Performance of the Hydrocylone at Different Overflow Orifices for Some Selected Grain Legumes

\begin{tabular}{|c|c|c|c|c|c|c|c|c|c|c|c|c|}
\hline \multirow{2}{*}{$\begin{array}{c}\text { Underflow } \\
\text { Orifice } \\
\text { Size } \\
(\mathbf{m m}) \\
\end{array}$} & \multicolumn{3}{|c|}{ Common Bean } & \multicolumn{3}{|c|}{ Cowpea } & \multicolumn{3}{|c|}{ Locust Bean } & \multicolumn{3}{|c|}{ Soybean } \\
\hline & $\mathbf{E}_{\mathrm{c}}$ & $\mathbf{E}_{\mathbf{h}}$ & $\eta_{\mathrm{s}}$ & $\mathbf{E}_{\mathbf{h}}$ & $\mathbf{E}_{\mathbf{h}}$ & $\eta_{\mathrm{s}}$ & $\mathbf{E}_{\mathbf{c}}$ & $\mathbf{E}_{\mathrm{h}}$ & $\eta_{\mathrm{s}}$ & $\mathbf{E}_{\mathrm{c}}$ & $\mathbf{E}_{\mathbf{h}}$ & $\eta_{\mathrm{s}}$ \\
\hline 10 & 25.03 & 69.77 & 17.46 & 21.40 & 74.97 & 16.04 & 7.48 & 96.21 & 7.20 & 21.18 & 72.82 & 15.42 \\
\hline 20 & 86.97 & 77.15 & 67.01 & 89.40 & 73.60 & 65.80 & 69.07 & 55.93 & 38.63 & 90.00 & 72.14 & 64.92 \\
\hline 30 & 94.10 & 6.57 & 6.18 & 92.84 & 8.79 & 8.16 & 80.51 & 24.93 & 20.07 & 91.22 & 7.16 & 6.53 \\
\hline
\end{tabular}

$\mathbf{E}_{\mathrm{c}}=\%$ Mass Recovery Underflow $\quad \mathbf{E}_{\mathrm{h}}=\%$ Mass Recovery Overflow $\quad \eta_{\mathrm{s}}=$ Separation Efficiency $(\%)$

\section{CONCLUSION}

The use of a hydrocyclone for separation of hulls from the cotyledons of some grain legumes is practicable. The performance of the hydrocyclone was optimum at $20 \mathrm{~mm}$ underflow orifice diameter with separation efficiencies of 67.01, 65.80, 38.63 and 64.92\% for common bean, cowpea, locust bean and soybean respectively. However, the separation efficiency of the hydrocyclone can be improved with special locking gate valve for the underflow orifice.

\section{REFERENCES}

[1]. Copeland, L. O. and McDonald, M. B. Principle of seed science and technology (Kluwer Academic Publishers, Norwell Massachusetts, 2001).

[2]. Ghadge, P. N., Shewalkar, S. V. and Wankhede, D. B. Effect of Processing Methods on Qualities of Instant Whole Legume.Pigeon Pea (Cajanus Cajan L.), Agricultural Engineering International - The CIGR E Journal. Manuscript FP 08004. Vol. X, 2008.

[3]. Ihekoronye, A. I. and Ngoddy, P. O. Integrated food science and technology for the tropics (Macmillian Publishers Ltd., London, 1985).

[4]. Ehiwe, A. O. F. and Reichert, R. D. Variability in Dehulling Quality of Cowpea, Pigeon Pea and Mug Bean Cultivars Determined with the Tangential Abrasive Dehulling Device, Cereal Chem. 64(2) 1986, 86-90.

[5]. Adewumi, B. A. and Igbeka, J. C. Performance Evaluation of a Burr Type Dehuller for Locust bean. Ondo State Polytechnic, Owo Research and Technical Journal, 5(1), 1996, 1-8.

[6]. Kethireddipalli, P., Hung, Y. E., McWatters, K. H. and Phillips, R. D. Effects of Milling Methods (Wet and dry) on the functional properties of Cowpea (Vigna unguiculata) pastes and end product (akara) quality. Journal of Food Science. 67(1), 2002, 48-52.

[7]. Ologungba, F. O. Development of Hydrocyclone Separator for Legumes. Proceedings of the $2^{\text {nd }}$ National Conference on Contemporary Issues in Technology and Development. Rufus Giwa Polytechnic, Owo, Nigeria. 2006, 367-374.

[8]. Svarovsky, L. and Thew, M. T. Hydrocyclones: Analysis and Applications (Kluwer Academic Publishers, London, 1992). 